\title{
Relationship Between Leptin and Neopterin Levels and Disease Activation Parameters in Patients With Rheumatoid Arthritis
}

\author{
Arif GÜLKESEN, ${ }^{1}$ Gürkan AKGÖL, ${ }^{1}$ Türkan TUNCER, ${ }^{2}$ Gül Ayden KAL, ${ }^{3}$ \\ Selda TELO,${ }^{4}$ Ahmet Kürşad POYRAZ, ${ }^{5}$ Arzu KAYA ${ }^{1}$ \\ ${ }^{1}$ Department of Physical Medicine and Rehabilitation, Medical Faculty of Firat University, Elazığ, Turkey \\ ${ }^{2}$ Department of Physical Medicine and Rehabilitation, Siirt State Hospital, Siirt, Turkey \\ ${ }^{3}$ Department of Physical Medicine and Rehabilitation, Elazığ Training and Research Hospital, Elazı̆̆, Turkey \\ ${ }^{4}$ Department of Biochemistry and Clinical Biochemistry, Medical Faculty of Firat University, Elaziğ, Turkey \\ ${ }^{5}$ Department of Radiology, Medical Faculty of Firat University, Elazığ, Turkey
}

\begin{abstract}
Objectives: This study aims to determine serum leptin and neopterin levels in patients with rheumatoid arthritis (RA) and investigate the relationship between clinical and laboratory parameters of disease activity and radiographic progression.

Patients and methods: The study included 33 RA patients ( 9 males, 24 females; mean age $52.5 \pm 12.3$ years; range 29 to 75 years) and age- and

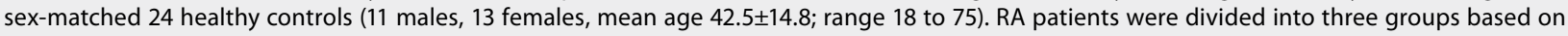
Disease Activity Scores in 28 joints (DAS28) as low disease activity, moderate disease activity, and high disease activity groups. Of the patients, 13 (39.4\%) had low disease activity (DAS28=2.6-3.2), 12 (36.4\%) had moderate disease activity (DAS28=3.2-5.1), and eight (24.2\%) had high disease activity (DAS28 $\geq 5.1$ ).

Results: Mean serum leptin and neopterin levels in the RA group were $23.98 \pm 18.88 \mathrm{ng} / \mathrm{mL}$ and $1.88 \pm 1.84 \mathrm{nmol} / \mathrm{L}$, respectively. Mean serum leptin and neopterin levels in the control group were $19.40 \pm 13: 42 \mathrm{ng} / \mathrm{mL}$ and $1.13 \pm 0.55 \mathrm{nmol} / \mathrm{L}$, respectively. There was no statistically significant difference in the levels of serum leptin $(p=0.674)$ and neopterin $(p=0.078)$ between RA patients and control group. Serum leptin $(p=0.574)$ and neopterin $(p=0.921)$ levels in RA patients and control group showed no correlation with body mass index levels. Besides, there was no correlation between age and plasma leptin and neopterin levels and rheumatoid factor positivity, anti-cyclic citrullinated peptide antibodies, disease duration, erythrocyte sedimentation rate, and C-reactive protein levels in RA group. In RA patients, there was no correlation between serum leptin and neopterin levels and clinical and laboratory parameters indicating the disease activity. In RA patients, there was also no correlation between radiographic joint damage and serum leptin and neopterin levels. A positive correlation was shown in RA patients between disease duration and modified Larsen $s c o r e(p=0.01)$. Conclusion: In our study, no correlation was detected between serum leptin and neopterin levels and disease activity parameters in RA patients. Therefore, leptin and neopterin levels may not be considered as beneficial inflammation parameters to be used in the diagnosis of RA and disease activation tracking.

Keywords: Disease activity; leptin; neopterin; rheumatoid arthritis.
\end{abstract}

Rheumatoid arthritis (RA) is a chronic systemic autoimmune inflammatory disease characterized by symmetric synovitis, progressive joint destruction, pain, fatigue, and disability. Although precise cause of this disease is not known, various proinflammatory cytokines including tumor necrosis factor-alpha (TNF- $\alpha$ ), interleukin- 1 , and interleukin-6 have been recognized as etiological factors. ${ }^{1-3}$ Leptin (Ob protein) which was discovered by Zhang et al. ${ }^{4}$ in the year 1994 is a single strand protein hormone containing 167 amino acids with a molecular weight of 16 kilodalton which structurally resembles cytokines. Increased leptin levels during infection and inflammation support the fact that leptin is a component of cytokine network which mediates immune 
response. Leptin plays an important role in the T-cell related inflammatory process and reportedly modulates T-helper cell activation in cellular immune response. ${ }^{5}$ Leptin activates monocyte/ macrophage cells and increases the production of proinflammatory cells as TNF- $\alpha$ and interleukin-6. Besides, it enables conversion of T-cells into Th1 phenotype and release of interleukin- 2 and interferon gamma. ${ }^{6}$

Neopterin is a pteridine derivative produced by monocytes and macrophages primarily as a response to interferon gamma stimulation induced by the activation of the cellular immune system. Measurement of neopterin in body fluids gives information about the level of cellular immune response and aids in the prediction of disease progression. ${ }^{7,8}$ Neopterin release starts three days before T-lymphocyte proliferation and peaks nearly one week before specific antibodies become positive. Furthermore, increased production of neopterin is observed. Therefore, neopterin may be used as an indicator of early stage inflammation. ${ }^{9,10}$

In this study, we aimed to determine serum leptin and neopterin levels in patients with RA and investigate the relationship between clinical and laboratory parameters of disease activity and radiographic progression.

\section{PATIENTS AND METHODS}

Thirty-three consecutive patients (9 males, 24 females; mean age $52.5 \pm 12.3$ years; range 29 to 75 years) with RA established based on revised 1987 American College of Rheumatology criteria, who were followed up in the Firat University Hospital, Rheumatology Clinic of Department of Physical Medicine and Rehabilitation between October 2015 and January 2016 as well as 24 age- and sex-matched healthy controls (11 males, 13 females, mean age $42.5 \pm 14.8$; range 18 to 75) who were selected from the hospital staff and visitors and who were not the relatives of the patients were included in the study. Mean disease duration was $9.5 \pm 7.2$ years. Approval from the institutional ethics committee was obtained and a written informed consent was obtained from each patient. The study was conducted in accordance with the principles of the Declaration of Helsinki. Patients with an autoimmune disease apart from
RA (excluding secondary Sjögren's syndrome), acute or chronic infections, malignancies, known pulmonary, hepatic or renal diseases, endocrinologic diseases or pregnant females were excluded.

Visual analog scale scores were used for global assessments of the patient, and the physician, and during routine clinical evaluations of all the patients which included assessments of pain, and fatigue. Morning stiffness was assessed based on the duration of morning stiffness in minutes. Disease activity was evaluated using Disease Activity Scores in 28 joints (DAS28) criteria including number of the tender or swollen joints, erythrocyte sedimentation rate (ESR), and global health assessments. Patients with DAS28 score of $\leq 3.2$ were evaluated as having lower disease activity, while DAS28 score of $>3.2$ indicated patients with high/moderate disease activity. ${ }^{11,12}$ Besides, patients were divided into two groups as patients with early stage RA (disease duration of $\leq 2$ years) and established RA (disease duration of $\geq 2$ years). Functional disability was evaluated using health assessment questionnaire scoring system. ${ }^{13}$

At 08:00-09:00 AM, blood samples were drawn from all the participants who had fasted overnight. Results of routine laboratory tests (ESR, C-reactive protein, blood biochemistry, whole blood count, urinalysis, rheumatoid factor (RF) and anti-cyclic citrullinated peptide (anti-CCP) were analyzed on the same day. RF was measured using nephelometry. Anti-CCP was evaluated by enzyme-linked immunosorbent assay. Blood samples to analyze leptin and neopterin levels were collected in citrated tubes and centrifuged at $2000 \mathrm{rpm}$ for 15 minutes. The harvested serum was stored at $-80{ }^{\circ} \mathrm{C}$. Serum neopterin (DRG Instruments, $\mathrm{GmbH}$, Germany; Catalogue no: EIA-1476) and leptin (DRG Instruments, GmbH, Germany; Catalogue no: EIA-2395) levels were determined by enzyme-linked immunosorbent assay method using commercial kits in compliance with the manufacturer's directives and expressed in $\mathrm{ng} / \mathrm{mL}$. Neopterin sensitivity was detected at $0.2 \mathrm{ng} / \mathrm{mL}$, while intra- and inter-assay coefficient of variations were $<9.5 \%$ and $<8.1 \%$, respectively. Leptin sensitivity was detected at $1.0 \mathrm{ng} / \mathrm{mL}$, while intra- and interassay coefficient of variations were $<6.9 \%$ and $<11.5 \%$, respectively. 
Standardized hand radiograms of all patients were obtained during the last six months. Destructive changes in hand joints were evaluated by an observer blinded to clinical and laboratory data of the patients using modified Larsen scoring system..${ }^{14}$ In this scoring system, a total of 24 points on joints of both hands were scored between 0 and 5 points to obtain the total score (minimum score: 0, maximum score: 120).

\section{Statistical analysis}

Data were analyzed using the SPSS version 15.0 software (SPSS Inc., Chicago, IL, USA). Parametric tests (independent-samples t-test) were applied to data of normal distribution and non-parametric tests (Mann-Whiney U-test) were applied to data of questionably normal distribution. The distribution of categorical variables in both groups was compared using Pearson chi-square test. Continuous data were presented as mean \pm standard deviation or median (minimum-maximum), as appropriate. All differences associated with a chance probability of $\mathrm{p}<0.05$ were considered statistically significant.

\section{RESULTS}

In the RA group, mean serum leptin and neopterin levels were $23.98 \pm 18.88 \mathrm{ng} / \mathrm{mL}$ and $1.88 \pm 1.84 \mathrm{nmol} / \mathrm{L}$, respectively. In the control group, mean serum leptin and neopterin levels were $19.40 \pm 13.42 \mathrm{ng} / \mathrm{mL}$ and $1.13 \pm 0.55 \mathrm{nmol} / \mathrm{L}$, respectively. No statistically significant difference was found between RA and control groups regarding serum leptin $(p=0.674)$ and neopterin $(p=0.078)$ levels.

Age, sex, and body mass index (BMI) of the patients were comparable between RA and control groups (Table 1). Duration of disease was $9.57 \pm 7.29$ years in the RA group. RF and anti-CCP positivity were detected in 26 patients (78.8\%). The patients had low (DAS28 $=2.6-3.2$; $\mathrm{n}=13 ; 39.4 \%$ ), moderate (DAS28 $=3.2-5.1 ; \mathrm{n}=12$ : $36.4 \%$ ), and high (DAS28 $\geq 5.1 ; n=8: 24.2 \%$ ) degrees of disease activity.

No correlation was observed between serum leptin $(p=0.574)$ and neopterin $(p=0.921)$ levels and $\mathrm{BMI}$ in RA and control groups. In the RA group, no correlation was detected between

Table 1. Comparison of demographic and clinical laboratory parameters of rheumatoid arthritis patients and healthy controls

\begin{tabular}{|c|c|c|c|c|c|c|c|}
\hline & \multicolumn{3}{|c|}{ Rheumatoid arthritis ( $\mathrm{n}=33$ ) } & \multicolumn{3}{|c|}{ Controls $(n=24)$} & \multirow[b]{2}{*}{$p$} \\
\hline & $\mathrm{n}$ & Mean \pm SD & Range & $\mathrm{n}$ & Mean \pm SD & Range & \\
\hline Age (years) & & $52.5 \pm 12.4$ & $29-75$ & & $42.5 \pm 14.8$ & $18-75$ & 0.009 \\
\hline \multicolumn{8}{|l|}{ Sex } \\
\hline Female & 24 & & & 13 & & & \\
\hline Male & 9 & & & 11 & & & \\
\hline Body mass index & & $32.0 \pm 5.1$ & $24.30-41$ & & $291 \pm 4.7$ & $23.30-40$ & 0.035 \\
\hline Duration of the disease (years) & & $9.6 \pm 7.3$ & $1-30$ & & & & \\
\hline Morning stiffness (min.) & & $55.9 \pm 64.5$ & $0-300$ & & & & \\
\hline Pain (0-100 mm VAS) & & $49.7 \pm 29.9$ & $0-100$ & & & & \\
\hline Fatigue (0-100 mm VAS) & & $5.0 \pm 33.2$ & $0-100$ & & & & \\
\hline \multicolumn{8}{|l|}{ Global assessments of the patient } \\
\hline (0-100 mm VAS) & & $46.4 \pm 21.3$ & $10-90$ & & & & \\
\hline Global assessments of the physician & & & & & & & \\
\hline (0-100 mm VAS) & & $29.7 \pm 20.8$ & $5-80$ & & & & \\
\hline Number of the swollen joints (0-28) & & $1.4 \pm 2.9$ & $0-14$ & & & & \\
\hline Number of the tender joints $(0-28)$ & & $6.0 \pm 5.9$ & $0-28$ & & & & \\
\hline Erythrocyte sedimentation rate $(\mathrm{mm} / \mathrm{h})$ & & $37.9 \pm 28.0$ & 4-96 & & $11.3 \pm 9.9$ & 3-33 & 0.000 \\
\hline$C$ reactive protein $(\mathrm{g} / \mathrm{dL})$ & & $4.0 \pm 7.5$ & 0.04-39 & & $1.1 \pm 1.2$ & $0.01-3.19$ & 0.013 \\
\hline Rheumatoid factor (IU/mL) & & $94.4 \pm 127.8$ & $1-672$ & & $7.9 \pm 3.9$ & $0.2-15$ & 0.000 \\
\hline Serum leptin & & $24.0 \pm 18.9$ & $8.09-95.10$ & & $19.4 \pm 13.4$ & $9.43-59.4$ & 0.674 \\
\hline Serum neopterin & & $1.9 \pm 1.8$ & $0.49-10.57$ & & $1.1 \pm 0.6$ & $0.55-3.37$ & 0.078 \\
\hline Disease Activity Score 28 (0-9.4) & & $4.3 \pm 1.5$ & $1.86-8.27$ & & & & \\
\hline Health Assessment Questionnaire $20(0-3)$ & & $1.4 \pm 0.7$ & 0.40-3 & & & & \\
\hline Anti-cyclic citrullinated peptide & & $352.6 \pm 378.0$ & $3-1000$ & & $11.9 \pm 5.7$ & $6-33.70$ & 0.000 \\
\hline Modified Larsen Score (0-120) & & $21.9 \pm 12.9$ & $8-52$ & & & & \\
\hline
\end{tabular}




\begin{tabular}{|c|c|c|c|c|}
\hline & \multicolumn{2}{|c|}{ Leptin } & \multicolumn{2}{|c|}{ Neopterin } \\
\hline & $p$ & $\mathrm{r}$ & $p$ & $\mathrm{r}$ \\
\hline Morning stiffness (min.) & 0.968 & -0.007 & 0.402 & -0.151 \\
\hline Pain (VAS) & 0.828 & 0.039 & 0.120 & -0.276 \\
\hline Nottingham Health Profile pain score & 0.922 & 0.018 & 0.595 & -0.096 \\
\hline Nottingham Health Profile fatigue score & 0.809 & -0.044 & 0.187 & -0.235 \\
\hline Nottingham Health Profile mobility score & 0.660 & 0.079 & 0.135 & -0.265 \\
\hline Nottingham Health Profile sleep score & 0.901 & -0.023 & 0.584 & 0.099 \\
\hline Nottingham Health Profile social score & 0.878 & 0.028 & 0.970 & -0.007 \\
\hline Nottingham Health Profile emotional score & 0.358 & 0.165 & 0.152 & -0.255 \\
\hline Global assessments of the patient (0-100 mm VAS) & 0.939 & -0.014 & 0.606 & -0.093 \\
\hline Global assessments of the physician (0-100 mm VAS) & 0.704 & 0.069 & 0.436 & -0.140 \\
\hline Number of the tender joints $(0-28)$ & 0.429 & 0.142 & 0.536 & -0.112 \\
\hline Number of the swollen joints $(0-28)$ & 0.546 & 0.109 & 0.837 & -0.037 \\
\hline Erythrocyte sedimentation rate $(\mathrm{mm} / \mathrm{h})$ & 0.954 & -0.010 & 0.904 & -0.022 \\
\hline$C$ reactive protein $(\mathrm{g} / \mathrm{dL})$ & 0.850 & 0.034 & 0.322 & 0.178 \\
\hline Anti-cyclic citrullinated peptide & 0.126 & -0.272 & 0.996 & -0.001 \\
\hline Rheumatoid factor (IU/mL) & 0.340 & -0.172 & 0.905 & 0.022 \\
\hline Disease Activity Score 28 & 0.681 & 0.074 & 0.292 & -0.189 \\
\hline Health Assessment Questionnaire $20(0-3)$ & 0.982 & 0.004 & 0.234 & -0.213 \\
\hline Body mass index $\left(\mathrm{kg} / \mathrm{m}^{2}\right)$ & 0.574 & 0.101 & 0.921 & 0.018 \\
\hline Modified Larsen Score & 0.973 & -0.006 & 0.560 & -0.105 \\
\hline
\end{tabular}

plasma leptin and neopterin levels, and age, RF positivity, anti-CCP positivity, disease duration, $\mathrm{ESR}$, and C-reactive protein levels.

There was no correlation between RA disease activation and serum leptin $(p=0.681)$ and neopterin $(p=0.292)$ levels. Mean serum leptin and neopterin levels were also indicated with low $(24.94 \pm 15.97 \mathrm{ng} / \mathrm{mL}$ vs $2.46 \pm 2.69$ $\mathrm{nmol} / \mathrm{L})$, moderate $(22.12 \pm 24.01 \mathrm{ng} / \mathrm{mL}$ vs $1.59 \pm 1.06 \mathrm{nmol} / \mathrm{L})$, andhigh $(25.20 \pm 16.66 \mathrm{ng} / \mathrm{mL}$ vs $1.39 \pm 0.50 \mathrm{nmol} / \mathrm{L})$ disease activities.

In RA group, no correlation was detected between serum leptin and neopterin levels and clinical and laboratory parameters which demonstrated disease activity (Table 2).

In the RA group, eight patients (24.2\%) had early-stage, while 25 patients $(75.8 \%)$ had established RA. In the subgroups of early-stage and established RA, no statistically significant difference was detected regarding serum leptin $(p=0.731)$ and neopterin $(p=0.880)$ levels. Similarly, serum leptin and neopterin levels were not related with radiographic score.

A significant difference was detected between RA and control groups regarding levels of C-reactive protein $(p=0.013)$, ESR $(p=0.000)$, anti-CCP $(p=0.000)$, and $R F(p=0.000)$. A positive correlation was detected between disease duration and modified Larsen score in patients with RA $(p=0.01)$.

All patients were receiving corticosteroid treatment. Five patients (15.2\%) were also on anti-TNF- $\alpha$ treatment. The remaining 28 patients (84.8\%) were receiving prednisolone and one or more than one disease-modifying antirheumatic drug including methotrexate, sulfosalazine, and hydroxychloroquine.

No statistically significantly difference was found between RA patients who received antiTNF- $\alpha$ or disease-modifying antirheumatic drug treatment in terms of serum leptin $(p=0.478)$ and neopterin $(p=0.827)$ levels.

\section{DISCUSSION}

Leptin is a protein hormone produced by adipocytes which also plays an important role in the regulation of metabolism. Leptin also affects other biological functions as immune process. As an immune modulator and proinflammatory indicator, the functions of leptin in immune system have been investigated in a few studies. Biological mechanism of the relationship between $\mathrm{RA}$ and leptin is not clear-cut. Studies have yielded 
diverse results regarding the role of leptin in the pathogenesis of RA and the relationship between leptin and disease activation in RA is debatable.

In our study, we detected no difference in serum leptin levels between RA patients and healthy controls. This result was similar to those observed in a few previous studies. ${ }^{15-19}$ However, Otero et al. ${ }^{20}$ and Bokarewa et al. ${ }^{21}$ showed significantly higher serum leptin levels in RA patients when compared with healthy controls. Contrarily, Tokarczyk-Knapik et al. ${ }^{22}$ demonstrated lower leptin levels in their control group.

Targonska-Stepniak et al. ${ }^{23}$ indicated that in patients with erosive RA, levels of leptin increased substantially which demonstrated a positive correlation with disease duration and activation. In our study, no correlation existed between serum leptin levels and modified Larsen score in patients with RA. However, Rho et al. ${ }^{24}$ detected a negative correlation between increased serum leptin levels and radiologically detected erosive disease.

Similar with some studies, in our study, serum leptin levels was not related with disease activity, the levels of acute phase reactants, the numbers of tender or swollen joints, and global assessments of the patient and the physician. ${ }^{15,16,19,22,25}$ However, a positive correlation was detected in RA patients between ESR, DAS28, and number of tender joints. ${ }^{23}$

In our study, no difference was observed in serum leptin levels in RA patients who received different treatment protocols. Similarly, Oner et al. ${ }^{15}$ did not detect a significant change in serum leptin levels in groups of RA patients who received different treatment protocols. Gunaydin et al. ${ }^{26}$ indicated lack of difference between serum leptin levels of RA patients treated with methotrexate. In a study by Härle et al., ${ }^{27}$ the authors reported that clinical and biochemical activation parameters of inflammation in RA patients treated with adalimumab had decreased without any change in leptin levels.

Serum leptin levels in the RA and control groups did not correlate with BMI in our study. Similarly, Oner et al. $^{15}$ did not demonstrate any correlation between RA, osteoarthritis, and control groups with respect to serum leptin levels and BMI. However, in some studies, no correlation was reported between serum leptin levels and BMI in patients with RA. ${ }^{16,17,25}$

Neopterin is a low molecular weight aromatic pteridin. With activation of guanosine triphosphate cyclohydrolase enzyme by guanosine triphosphate, it is converted to 7,8-dihydroneopterin triphosphate, and from this molecule, 5,6,7,8-tetrahydrobiopterin or neopterin can be synthetized. Contrary to other human cells which synthetize 5,6,7,8-tetrahydrobiopterin, monocyte-macrophages produce neopterin from guanosine triphosphate due to lack of 6-pyruvoyl tetrahydropterin synthase enzyme. ${ }^{28,29}$ Synthesis of neopterin is induced by interferon gamma, TNF- $\alpha$, granulocyte-macrophage colony stimulating factor, and lipopolysaccharides. ${ }^{30,31}$ Since undifferentiated form of neopterin is released and this form is found in body fluids, it is a good marker indicating activation of immunity and inflammation. Increased neopterin concentrations have been demonstrated in infection, autoimmune diseases, cancer, renal failure, coronary artery disease, and allograft rejections. ${ }^{32-37}$

Similar to results obtained by Ozkan et al., ${ }^{38}$ we found no difference between serum neopterin concentrations of patients with RA and healthy controls in our study. However, Schroecksnadel et al. ${ }^{28}$ and D'agostino et al. ${ }^{39}$ showed higher levels of neopterin levels in patients with RA when compared with those of the controls. Besides, Shady et al. $^{40}$ detected higher serum neopterin levels in patients with juvenile idiopathic arthritis compared to those of the control group. In a study by Hausen et al., ${ }^{41}$ increased neopterin levels were detected in osteoarthritis patients when compared to RA patients.

Ozkan et al. ${ }^{38}$ detected a correlation between neopterin, ESR, and RF in patients with RA; while we detected no correlation between these parameters in our RA patients.

In our study, while we showed no correlation between neopterin levels and clinical and biochemical activation parameters of the disease in RA patients, D'agostino et al. ${ }^{39}$ detected a positive correlation between DAS28 and neopterin levels.

This study has some limitations. The main limitation is the study's cross-sectional design. Also, the sample size may be small to reach a 
definitive judgment. Furthermore, power analysis was not performed and only serum leptin and neopterin levels were analyzed.

In conclusion, serum leptin and neopterin levels did not increase and they were not correlated with disease activation parameters in patients with RA. Chronic inflammation and BMI might affect serum leptin and neopterin levels. Therefore, further studies are needed to explain the relationship between leptin and neopterin levels, and inflammation.

\section{Declaration of conflicting interests}

The authors declared no conflicts of interest with respect to the authorship and/or publication of this article.

\section{Funding}

The authors received no financial support for the research and/or authorship of this article.

\section{REFERENCES}

1. Smolen JS, Aletaha D, Koeller M, Weisman MH, Emery P. New therapies for treatment of rheumatoid arthritis. Lancet 2007;370:1861-74.

2. Firestein GS. Evolving concepts of rheumatoid arthritis. Nature 2003;423:356-61.

3. Arend WP. Physiology of cytokine pathways in rheumatoid arthritis. Arthritis Rheum 2001;45:101-6.

4. Zhang Y, Proenca R, Maffei M, Barone M, Leopold L, Friedman JM. Positional cloning of the mouse obese gene and its human homologue. Nature 1994;372:425-32.

5. Allam A, Radwan A. The relationship of serum leptin levels with disease activity in Egyptian patients with rheumatoid arthritis. The Egyptian Rheumatologist 2012;34: 185-90.

6. Zarkesh-Esfahani H, Pockley G, Metcalfe RA, Bidlingmaier M, Wu Z, Ajami A, et al. High-dose leptin activates human leukocytes via receptor expression on monocytes. J Immunol 2001;167:4593-9.

7. Berdowska A, Zwirska-Korczala K. Neopterin measurement in clinical diagnosis. J Clin Pharm Ther 2001;26:319-29.

8. Hoffmann G, Wirleitner B, Fuchs D. Potential role of immune system activation-associated production of neopterin derivatives in humans. Inflamm Res 2003;52:313-21.

9. Fuchs D, Weiss G, Wachter H. Neopterin, biochemistry and clinical use as a marker for cellular immune reactions. Int Arch Allergy Immunol 1993;101:1-6.

10. Dhont JL, Walter MP, Bauters F, Jouet JP. Neopterins in clinical medicine. Lancet 1988;1:509-11.
11. Prevoo ML, van 't Hof MA, Kuper HH, van Leeuwen MA, van de Putte LB, van Riel PL. Modified disease activity scores that include twenty-eight-joint counts. Development and validation in a prospective longitudinal study of patients with rheumatoid arthritis. Arthritis Rheum 1995;38:44-8.

12. Servais J, Hainaut M, Schmitz V, Maes P, Fransen K, Vaira $\mathrm{D}$, et al. Resistance testing in children changing human immunodeficiency virus type 1 protease inhibitor. Pediatr Infect Dis J 2002;21:214-20.

13. Küçükdeveci AA, Sahin H, Ataman S, Griffiths B, Tennant A. Issues in cross-cultural validity: example from the adaptation, reliability, and validity testing of a Turkish version of the Stanford Health Assessment Questionnaire. Arthritis Rheum 2004;51:14-9.

14. Larsen A. How to apply Larsen score in evaluating radiographs of rheumatoid arthritis in long-term studies. J Rheumatol 1995;22:1974-5.

15. Oner SY, Volkan O, Oner C, Mengi A, Direskeneli H, Tasan DA. Serum leptin levels do not correlate with disease activity in rheumatoid arthritis. Acta Reumatol Port 2015;40:50-4.

16. Hizmetli S, Kisa M, Gokalp N, Bakici MZ. Are plasma and synovial fluid leptin levels correlated with disease activity in rheumatoid arthritis? Rheumatol Int 2007;27:335-8.

17. Anders HJ, Rihl M, Heufelder A, Loch O, Schattenkirchner M. Leptin serum levels are not correlated with disease activity in patients with rheumatoid arthritis. Metabolism 1999;48:745-8.

18. Wislowska M, Rok M, Jaszczyk B, Stepien K, Cicha M. Serum leptin in rheumatoid arthritis. Rheumatol Int 2007;27:947-54.

19. Popa C, Netea MG, Radstake TR, van Riel PL, Barrera $\mathrm{P}$, van der Meer JW. Markers of inflammation are negatively correlated with serum leptin in rheumatoid arthritis. Ann Rheum Dis 2005;64:1195-8.

20. Otero M, Lago R, Gomez R, Lago F, Dieguez C, Gómez-Reino JJ, et al. Changes in plasma levels of fat-derived hormones adiponectin, leptin, resistin and visfatin in patients with rheumatoid arthritis. Ann Rheum Dis 2006;65:1198-201.

21. Bokarewa M, Bokarew D, Hultgren O, Tarkowski A. Leptin consumption in the inflamed joints of patients with rheumatoid arthritis. Ann Rheum Dis 2003;62:952-6.

22. Tokarczyk-Knapik A, Nowicki M, Wyroslak J. The relation between plasma leptin concentration and body fat mass in patients with rheumatoid arthritis. Pol Arch Med Wewn 2002;108:761-7. [Abstract]

23. Targonska-Stepniak B, Majdan M, Dryglewska M. Leptin serum levels in rheumatoid arthritis patients: relation to disease duration and activity. Rheumatol Int 2008;28:585-91.

24. Rho YH, Solus J, Sokka T, Oeser A, Chung CP, Gebretsadik T, et al. Adipocytokines are associated with radiographic joint damage in rheumatoid arthritis. Arthritis Rheum 2009;60:1906-14. 
25. Nishiya K, Nishiyama M, Chang A, Shinto A, Hashimoto K. Serum leptin levels in patients with rheumatoid arthritis are correlated with body mass index. Rinsho Byori 2002;50:524-7. [Abstract]

26. Gunaydin R, Kaya T, Atay A, Olmez N, Hur A, Koseoglu M. Serum leptin levels in rheumatoid arthritis and relationship with disease activity. South Med J 2006;99:1078-83.

27. Härle $P$, Sarzi-Puttini $P$, Cutolo M, Straub RH. No change of serum levels of leptin and adiponectin during anti-tumour necrosis factor antibody treatment with adalimumab in patients with rheumatoid arthritis. Ann Rheum Dis 2006;65:970-1.

28. Schroecksnadel K, Murr C, Winkler C, Wirleitner B, Fuith LC, Fuchs D. Neopterin to monitor clinical pathologies involving interferon- $\gamma$ production. Pteridines 2004;15:75-90.

29. Hamerlinck FF. Neopterin: a review. Exp Dermatol 1999;8:167-76.

30. Berdowska A, Zwirska-Korczala K. Neopterin measurement in clinical diagnosis. J Clin Pharm Ther 2001;26:319-29.

31. Werner ER, Werner-Felmayer G, Fuchs D, Hausen A, Reibnegger R, Yim JJ, et al. Biochemistry and function of pteridine synthesis in human and murine macrophages. Pathobiology 1991;59:276-9.

32. Pascual C, Karzai W, Meier-Hellmann A, Oberhoffer M, Horn A, Bredle D, et al. Total plasma antioxidant capacity is not always decreased in sepsis. Crit Care Med 1998;26:705-9.

33. Wagner R, Hayatghebi S, Rosenkranz M, Reinwein D. Increased serum neopterin levels in patients with Graves' disease. Exp Clin Endocrinol 1993;101:249-54.

34. Reibnegger G, Krainer M, Herold M, Ludwig H, Wachter H, Huber H. Predictive value of interleukin-6 and neopterin in patients with multiple myeloma. Cancer Res 1991;51:6250-3.

35. Oda K, Arai T, Nagase M. Increased serum and urinary neopterin in nephrotic syndrome indicate cell-mediated immune dysfunction. Am J Kidney Dis 1999;34:611-7.

36. Weiss G, Willeit J, Kiechl S, Fuchs D, Jarosch E, Oberhollenzer $\mathrm{F}$, et al. Increased concentrations of neopterin in carotid atherosclerosis. Atherosclerosis 1994;106:263-71.

37. Reibnegger G, Aichberger C, Fuchs D, Hausen A, Spielberger M, Werner ER, et al. Posttransplant neopterin excretion in renal allograft recipients--a reliable diagnostic aid for acute rejection and a predictive marker of long-term graft survival. Transplantation 1991;52:58-63.

38. Ozkan Y, Mete G, Sepici-Dincel A, Sepici V, Simsek B. Tryptophan degradation and neopterin levels in treated rheumatoid arthritis patients. Clin Rheumatol 2012;31:29-34.

39. D'agostino LE, Ventimiglia F, Verna JA, Colina Ade L, Aguirre Y, Arturi A, et al. Correlation between DAS-28 and neopterin as a biochemical marker of immune system activation in early rheumatoid arthritis. Autoimmunity 2013;46:44-9.

40. Shady MM, Fathy HA, Ali A, Youness ER, Fathy GA. Association of neopterin as a marker of immune system activation and juvenile rheumatoid arthritis activity. J Pediatr (Rio J) 2015;91:352-7.

41. Hausen A, Fuchs D, Reibnegger G. Neopterin as index for activity of disease in patients with rheumatoid arthritis. In: Curtius HC, Pfleiderer H, Wachter H, editors. Biomedical and clinical aspects of pteridines. Vol. 2. Berlin-New York: Walter de Gruyter; 1983. p. 245-54. 